\title{
Temperature-dependent appearance of forensically useful flies on carcasses
}

\author{
Szymon Matuszewski • Michal Szafalowicz • \\ Andrzej Grzywacz
}

Received: 21 June 2013 / Accepted: 17 September 2013 /Published online: 6 October 2013

(C) The Author(s) 2013. This article is published with open access at Springerlink.com

\begin{abstract}
Flies are frequently used for postmortem interval (PMI) estimations. These estimates are usually based on the age of larval or pupal specimens. However, the age defines only the minimum PMI. In order to move forensic entomology further, a method useful for the estimation of an interval preceding insect appearance on a corpse called the preappearance interval (PAI) is needed. Recently, it was demonstrated that the PAI of several carrion beetles is closely related to the temperature prevailing throughout this interval. Hence, it was postulated to estimate PAI from temperature. In order to check premises for using this approach with flies, a test of the relationship between adult or oviposition PAI and temperature was made for nine species of European flies. Data on PAI originated from pig carcasses decomposing under various temperatures. Adult PAI of Hydrotaea dentipes, Hydrotaea ignava, Hydrotaea similis, Phormia regina, and Stearibia nigriceps and oviposition PAI of $S$. nigriceps were exponentially related to temperature. Only $S$. nigriceps revealed a close relationship, demonstrating solid premises for PAI estimation from temperature alone. Adult and oviposition PAI of Calliphora vomitoria and adult PAI of Hydrotaea pilipes were not related to temperature. Adult and oviposition PAI of Lucilia sericata and Lucilia caesar responded similarly, with an abrupt and large increase in a narrow range of low temperatures and no response in a broad range of high temperatures. Probably, different mechanisms form the basis for the response of PAI to temperature in flies colonizing
\end{abstract}

S. Matuszewski $(\bowtie) \cdot$ M. Szafałowicz

Laboratory of Criminalistics, Adam Mickiewicz University,

Św. Marcin 90, 61-809 Poznań, Poland

e-mail: szymmat@amu.edu.pl

A. Grzywacz

Department of Animal Ecology, Nicolaus Copernicus University, Lwowska 1, 87-100 Torun, Poland carcasses shortly after death and flies colonizing carcasses later in the decomposition process.

Keywords Forensic entomology · Postmortem interval · Pre-appearance interval $\cdot$ Lucilia $\cdot$ Phormia $\cdot$ Calliphora . Hydrotaea $\cdot$ Stearibia

\section{Introduction}

Postmortem interval (PMI) may be estimated from the development or the succession of insects on corpses [1-5]. Entomological estimates are most frequently based on the age of larval or pupal specimens sampled from a corpse [1-5]. However, the age of an insect alone may define only the minimum PMI, as it gives information just about a development interval. Unfortunately, the age of an insect gives no information about an interval which precedes the appearance of a given specimen on a corpse which is named the preappearance interval (PAI) or the pre-colonization interval [6]. In the case of early arriving insects (e.g., blowflies), the minimum PMI is usually close to the actual PMI, but in the case of middle and late arriving insects, it defines actual PMI with the intrinsic and frequently very high inaccuracy. This is probably the main reason why middle and late arriving insects are rarely used for PMI estimation. However, even with the early arriving insects, the minimum PMI may be far from the actual PMI, as was exemplified by results of European, early spring carrion studies in which blowflies colonized carcasses with a delay of several days [7, 8]. Accordingly, in order to move forensic entomology further, a robust method for PAI estimation is needed.

In casework, an estimate of PAI may be reached through a qualitative evaluation of factors which delay colonization of carcasses by insects or through a reference to results of caserelevant pig carrion studies. Due to the lack of transparency 
and inapplicability to middle and late arriving insects, the first approach is inadequate for routine use. The second approach is, however, clearly impractical because it needs unattainable quantity of data from pig carrion studies. Recently, a novel approach was proposed. It was demonstrated that adult or larval PAI of some forensically important insects (particularly beetles) are closely related to the temperature prevailing in the corpse surrounding throughout the PAI [9-12]. Hence, it was postulated to estimate PAI from temperature, and several methods useful for that purpose were initially tested $[9,10]$. This approach has several advantages. First, previous works demonstrated that models of the relationship between PAI and temperature give accurate estimates for cases from different habitats, seasons, and biogeographic areas $[9,10]$. These results suggest that PAI may be estimated using case-specific temperature data and a species and stage-specific model for the relationship between PAI and temperature. Second, temperature is an elementary factor, and as such, it may be easily combined with other elementary factors (e.g., air humidity), if multifactor models for the relationship will be needed. Third, temperatures are the only case-specific data required by the method, and they may be gathered with well-defined and easily applicable protocols for measurement and retrospective correction [13-15].

In order to use the temperature approach to PAI estimation, the relationship between PAI and temperature should be close. It was found that several forensically important species of beetles meet this requirement [11]. However, no previous work tested the relationship in forensically important flies, insects which are most frequently used for the estimation of PMI $[16,17]$. There are flies which colonize carcasses immediately after death, as for example Calliphoridae or Sarcophagidae, but there are also flies which colonize corpses later in the decomposition process, e.g., Muscidae, Fanniidae, or Piophilidae [8, 18-22]. A temperature method for the estimation of PAI would be particularly useful in the case of the latter group of flies. In order to calibrate the method for these flies, a much better insight into the relationship between $\mathrm{PAI}$ of carrion flies and temperature is necessary. Hence, in this article, the relationship is tested for several forensically important European species of flies.

\section{Materials and methods}

Experimental design

In order to collect PAI data from a broad range of temperatures, carcasses were separated in time and space. The study was divided into six placements: 18 April (four pigs), 15 June (six pigs), 4 July (six pigs), 21 July (four pigs), 16 August (four pigs), and 30 August (six pigs) of 2011. In each placement, half of carcasses were exposed in forest habitats (hornbeam-oak forest, alder forest, and birch forest) and half in open habitats (xerothermic grasslands, sparse clumps of young birches in grasslands, and edges of grasslands and pine-oak or birch forests). This design assumes that the effect of season or habitat on PAI reduces itself to the effect of temperature specific for that season or habitat.

The experiment was conducted in the Biedrusko Military Range (Western Poland, Europe). In order to decrease migrations of immature insects and joint attraction by carcasses, they were far away from each other by at least $50 \mathrm{~m}$ (the distance between particular pigs was, in most cases, much larger, e.g., "open" and "forest" carcasses by about 2-3 km).

Table 1 Ranges in PAI and temperature for particular species

\begin{tabular}{|c|c|c|c|c|c|}
\hline Family & Species & Stage & $N$ & PAI range [days] & Temperature range $\left[{ }^{\circ} \mathrm{C}\right]$ \\
\hline \multirow[t]{7}{*}{ Calliphoridae } & \multirow[t]{2}{*}{ Calliphora vomitoria (Linnaeus, 1758) } & A & 25 & $0.2-9.4$ & $13.0-23.3$ \\
\hline & & $\mathrm{E}$ & 19 & $0.2-26.3$ & $13.3-21.6$ \\
\hline & \multirow[t]{2}{*}{ Lucilia caesar (Linnaeus, 1758) } & A & 26 & $0.2-3.2$ & $14.0-33.7$ \\
\hline & & $\mathrm{E}$ & 26 & $0.2-3.4$ & $13.5-33.7$ \\
\hline & \multirow[t]{2}{*}{ Lucilia sericata (Meigen, 1826) } & A & 15 & $0.2-5.2$ & $14.0-25.1$ \\
\hline & & $\mathrm{E}$ & 14 & $0.4-12.2$ & $15.4-25.1$ \\
\hline & Phormia regina (Meigen, 1826) & A & 25 & $1.2-8.4$ & $14.8-25.5$ \\
\hline \multirow[t]{4}{*}{ Muscidae } & Hydrotaea dentipes (Fabricius, 1805) & $\mathrm{A}$ & 15 & $0.3-11.0$ & $13.2-24.4$ \\
\hline & Hydrotaea ignava (Harris, 1780) & A & 16 & $2.2-24.3$ & $12.5-23.8$ \\
\hline & Hydrotaea pilipes Stein, 1903 & A & 21 & $2.3-12.3$ & $13.8-20.6$ \\
\hline & Hydrotaea similis Meade, 1887 & A & 20 & $0.3-11.0$ & $12.8-19.5$ \\
\hline \multirow[t]{2}{*}{ Piophilidae } & \multirow[t]{2}{*}{ Stearibia nigriceps (Meigen, 1826) } & $\mathrm{A}$ & 23 & $3.4-23.3$ & $12.3-23.5$ \\
\hline & & $\mathrm{E}$ & 22 & $8.3-37.3$ & $13.3-22.4$ \\
\hline
\end{tabular}

$A$ adult stage, $E$ egg stage 


\section{Carcasses}

In total, 30 domestic pig carcasses of similar mass (mean= $23 \mathrm{~kg}$; range $=11.4-56.7 \mathrm{~kg}$ ) were bought from a local pig farm. Pigs were killed at about 6A.M. (a blow to the base of the skull) and, after 1 to $3 \mathrm{~h}$, were exposed in the field. Carcasses were laid down on a metal grating and were protected with welded wire mesh.

\section{Sampling of flies}

Flies were sampled three times during the first day (after exposition, i.e., 1-3 h postmortem and then 4-6 and 10-11 h postmortem), two times a day for the following 5 days (between 10A.M. and 1 P.M. and between 4 and 6P.M.), and then once a day for the rest of the study (usually between 11 A.M. and 2 P.M.). The sampling was more frequent during the first days postmortem, as we wanted to increase the accuracy of PAI determinations for the early arriving flies. Two researchers performed the morning inspections, whereas the afternoon inspections were made by one person. The former lasted about $30 \mathrm{~min}$ and the latter about $15 \mathrm{~min}$.

Samples included pitfall trap, aerial sweep net, manual and soil collections. Two traps (diameter $=16 \mathrm{~cm}$, height $=17 \mathrm{~cm}$, $50 \%$ ethylene glycol) were buried dorsally and ventrally to the carcass. Adult flies were collected with a swatting technique, performed twice using large aerial sweep net (diameter $=55 \mathrm{~cm}$ ). Manual sampling focused on the surface of a carcass and soil under and near the carcass. It lasted about 5 min. Trap, net, and manual collections were taken at every inspection. Samples were preserved in $70 \%$ ethanol. Soil sampling started after termination of bloating and was made for the subsequent 2-3 weeks (every second day during the morning inspections). Samples (about $700 \mathrm{ml}$ ) were manually screened for larger insects and, afterwards, were put into the Tullgren funnels for 2 days.

Flies were determined using keys for identification [23-26] and collections of authors. In order to time oviposition, eggs were sampled for rearing purposes. Larvae were kept on pork in $20^{\circ} \mathrm{C}$ until adults emerged. Rearing containers were filled with vermiculite (Calliphoridae) or sand (Piophilidae).

\section{Temperature measurements}

Because carcasses were exposed on the ground, ground-level temperature was measured. HOBO U23 Pro v2 2× External Temperature Data Loggers (Onset Computer Corporation, Bourne, MA, USA) were used with sensors positioned on the ground (one dorsally and one ventrally to the carcass). Sensors were not protected in any way (debris, plants, etc. were carefully removed). Logging started at 6A.M. of the first day and 5-min logging intervals were used. Temperatures relevant for every PAI were averaged separately for each sensor and then a single mean was calculated.
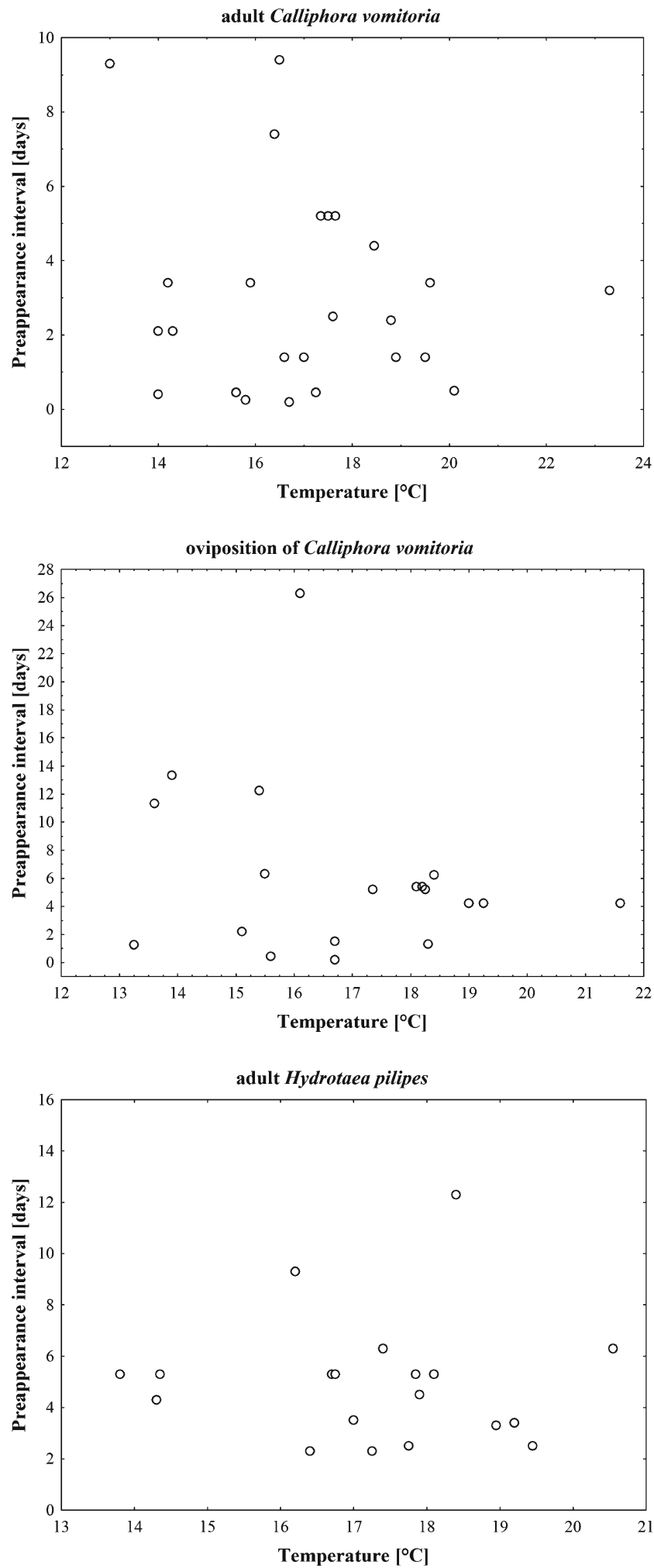

Fig. 1 The PAI and ground-level temperatures averaged for the duration of PAI for C. vomitoria and $H$. pilipes 
Data analyses

The relationship between PAI and temperature was tested separately for the adult PAI and the oviposition PAI. The adult PAI is an interval from the moment of death until the arrival of first adult insect of a given species. The oviposition PAI is an interval from the moment of death until the appearance of the first eggs of a given species. The relationship between the oviposition PAI and temperature was analyzed for Calliphora vomitoria, Lucilia caesar, Lucilia sericata (Calliphoridae), and Stearibia nigriceps (Piophilidae). As for the other species, there were only singular observations which precluded any robust analyses.

The relationship was modeled from at least 14 observations (Table 1). Data sets usually covered a broad range of temperatures (Table 1). In order to check for colinearity, scatter plots were made. As expected, for most species, the relationship was exponential with a clear representation for the minimum PAI. Consequently, the exponential model with asymptote displaced from zero was fitted (PAI $=c+e^{\left(b_{0}+b_{1} \times \text { temperature }\right)}$, where $c$ is "the minimum PAI," $e$ is "the base of the natural logarithm," $b_{0}$ and $b_{1}$ are parameters responsible for the shape of the curve). Because the estimate of $c$ regularly differed from the observed minimum PAI, models with $c$ fixed a priori were also tested. Graphs are given for models with estimated $c$, equations for both types of models. Parameters were approximated with the Levenberg-Marquardt procedure.

For species which revealed no relationship, only scatter plots are given. For species with statistically insignificant relationship, scatter plots and models with estimated $c$ are presented. For the other species, both types of models and lower temperature (LT) thresholds are given. LT thresholds were determined using the method of the least coefficient of variation in accumulation of degree-days [11]. For all analyses, the $5 \%$ level of significance was accepted. Calculations were made using Statistica 9.1 (StatSoft, Inc., 2010).
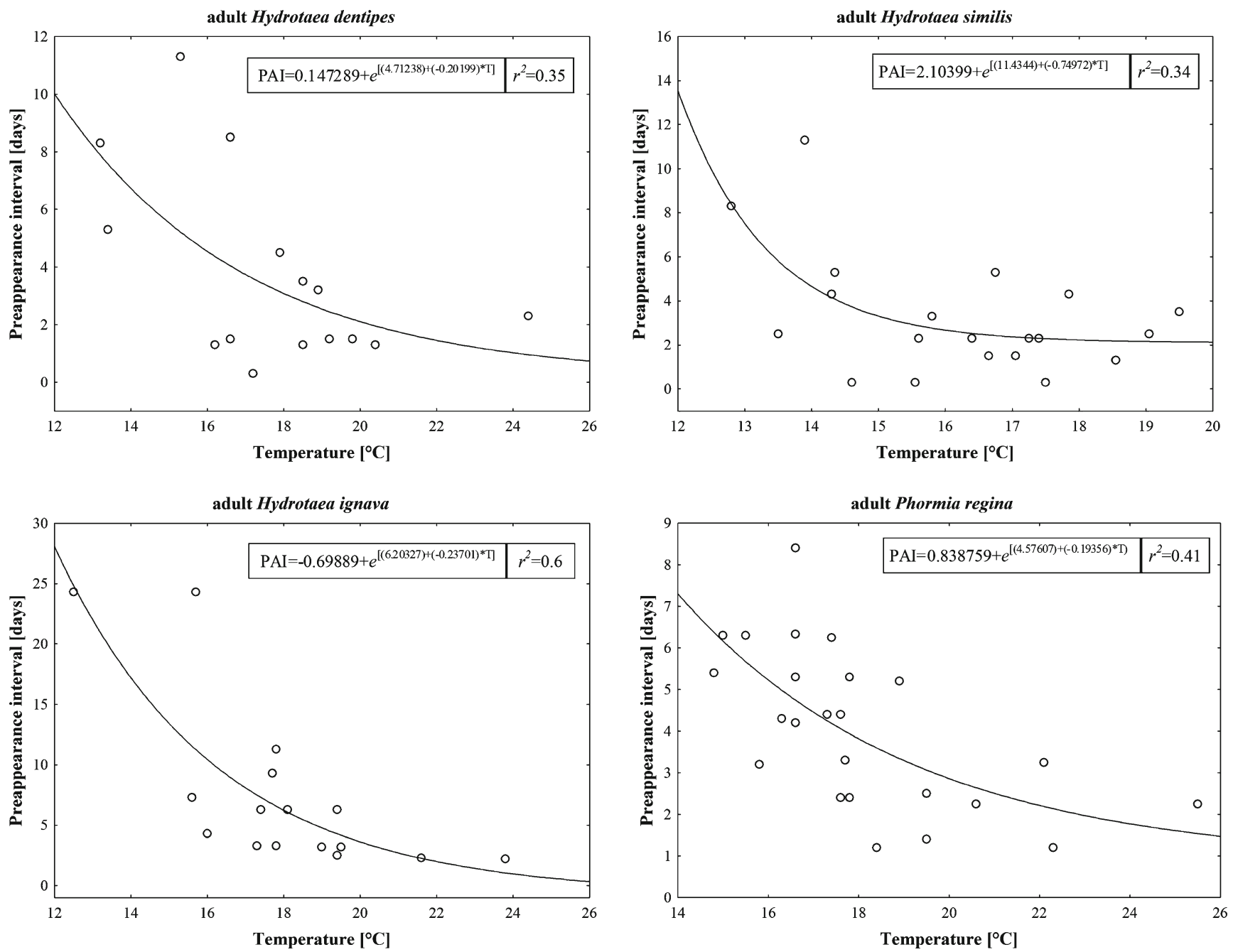

Fig. 2 The relationship between the PAI of selected Muscidae and Calliphoridae and ground-level temperatures averaged for the duration of PAI $(T)$ 


\section{Results}

Adult and oviposition PAI of $C$. vomitoria and adult PAI of Hydrotaea pilipes showed no relation to temperature at all (Fig. 1). Adult PAI of Hydrotaea dentipes, Hydrotaea ignava, Hydrotaea similis, and Phormia regina were exponentially related to temperature with a clear representation of the minimum PAI, however, with no statistical significance (nonlinear regression, $t$ test for $b_{1}, P=0.47,0.11,0.19$, and 0.3 respectively; Fig. 2). Adult and oviposition PAI of S. nigriceps were exponentially and significantly associated to temperature with evident representation of the minimum PAI (nonlinear regression, $t$ test for $b_{1}, P<0.001$; Fig. 3). LT thresholds for $S$. nigriceps were $11.3{ }^{\circ} \mathrm{C}$ for the adult PAI and $11.4{ }^{\circ} \mathrm{C}$ for the oviposition PAI (Table 2).

Adult and oviposition PAI of $L$. caesar and $L$. sericata responded similarly to temperature (Fig. 4). In a high temperature range, PAI was more or less constant and unrelated to
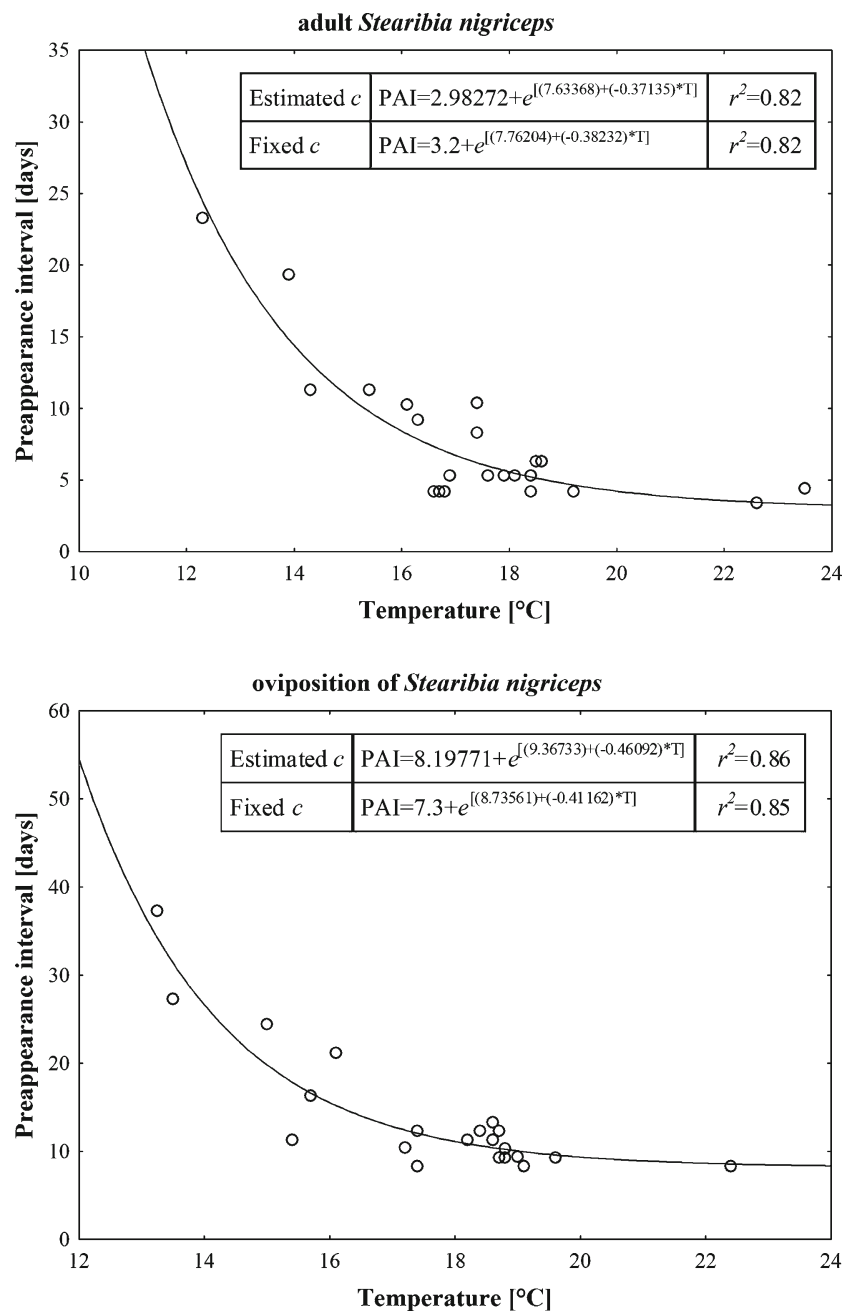

Fig. 3 The relationship between the PAI of S. nigriceps and ground-level temperatures averaged for the duration of PAI $(T)$. Graphs represent models with estimated $c$
Table 2 LT thresholds and accumulations of degree-days (ADD) for the adult and oviposition PAI of $S$. nigriceps

\begin{tabular}{lllllll}
\hline PAI & LT $\left[{ }^{\circ} \mathrm{C}\right]$ & \multicolumn{2}{l}{ ADD } & & $\begin{array}{l}\text { Coefficient } \\
\text { of variation } \\
\text { in ADD [\%] }\end{array}$ \\
\cline { 3 - 7 } & & Mean & $N$ & $\begin{array}{l}\text { Standard } \\
\text { error }\end{array}$ & Range & \\
\hline Adult & 11.3 & 39.29 & 23 & 2.32 & $23.2-64.3$ & 28.32 \\
Oviposition & 11.4 & 75.57 & 22 & 3.07 & $45.1-109.3$ & 19.04 \\
\hline
\end{tabular}

temperature (Fig. 4). Under daily average temperatures above $17^{\circ} \mathrm{C}$, the oviposition of $L$. caesar was always recorded within the first $12 \mathrm{~h}$ postmortem, whereas in the case of $L$. sericata, it started, in each case, with temperatures above $18{ }^{\circ} \mathrm{C}$ within the first $35 \mathrm{~h}$ after death (Fig. 4). In a low temperature range, adult and oviposition PAI of $L$. caesar responded erratically to the temperature with some cases near the minimum PAI and some cases largely above the minimum PAI (Fig. 4). In the case of $L$. sericata, the response of PAI to low temperature was similar, although less erratic (Fig. 4). For both species and both kinds of PAI, the low temperature change in PAI may be represented by a near-vertical line (Fig. 4).

\section{Discussion}

Previous results indicate that an exponential decrease in PAI with an increase in temperature is a general model for the relationship between PAI and temperature in carrion insects [11]. Current results partly support this proposition. For most species of flies, PAI decreased exponentially with an increase in average daily temperatures. A clear exception was only adult and oviposition PAI of $L$. caesar and L. sericata, in which case lack of response in a high temperature range was followed by an abrupt and large increase in PAI in a narrow range of low temperatures. In order to understand this unusual response, one should look at factors governing the attraction of insects to carcasses.

Carrion insects respond to volatile organic compounds emitted from a decomposing carcass [27-32]. For example L. sericata and $L$. caesar are attracted by oligosulfides, in particular dimethyl disulfide [27, 29], which is formed early in carrion decomposition from the sulfur-containing amino acids $[33,34]$. These results indicate that the emission of relevant attractants is the most important precondition for the appearance of insects on a carcass. Consequently, it was suggested that processes in which attractants are generated depend on temperature, and as a result, PAI for most carrion insects is also temperature-dependent $[9,10]$. Previous [9-11] and current models for $S$. nigriceps, $P$. regina, and species of Hydrotaea support this hypothesis. However, the unusual pattern of PAI response to temperature, as recorded for both 

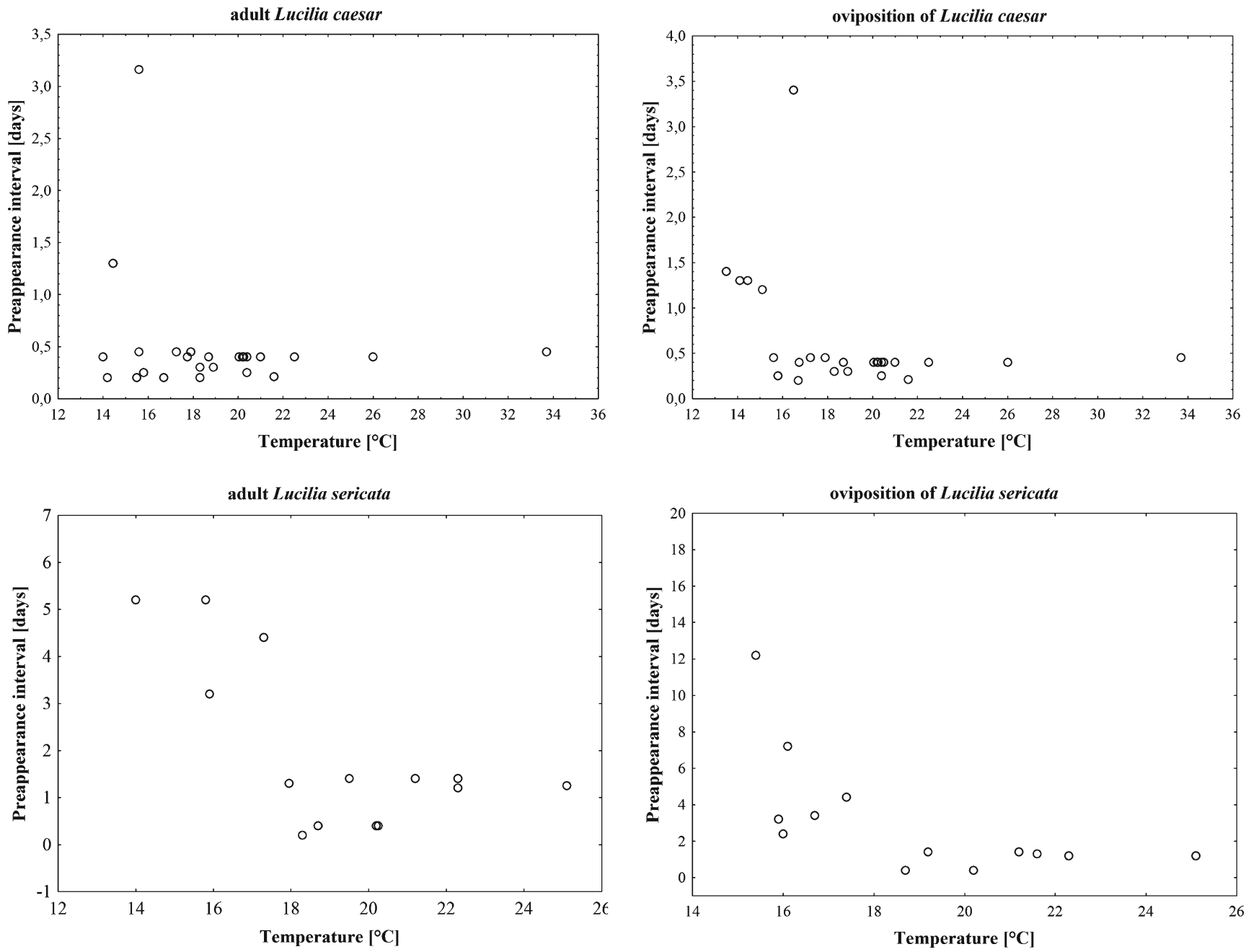

Fig. 4 The PAI and ground-level temperatures averaged for the duration of PAI for L. caesar and L. sericata

species of Lucilia, indicates that the processes-oriented hypothesis may not be valid for all carrion insects.

Apart from the presence of VOCs, there are two classes of factors which may potentially affect PAI: factors related to the release of attractants and factors related to the activity of insects (for a broad discussion of factors affecting colonization of carcasses by flies, see [35]). The first group is composed of barriers of any kind for attractants. However, they are irrelevant for the current results; hence, they will not be discussed here. The second class are abiotic mediators of insect activity, e.g., air temperature or humidity [36,37], repellents [38-40], or the time of the day [41-45] and biotic mediators of insect activity, e.g., group oviposition effects [46] or ovarian development status. From this point of view, air temperature seems to be particularly important for the current results. It was found that ambient air temperature is a positive predictor for visitation on non-odor sticky traps by adult Lucilia flies [47] and for blowfly oviposition on a beef liver bait [37]. These results directly demonstrate that forensically relevant aspects of blowfly activity are mediated by temperature. Species of Lucilia have high temperature thresholds for the activity, as was recently exemplified by Richards et al. [36] for South African L. sericata, which revealed the onset of coordinated muscle activity (i.e., standing) at a temperature of about $21{ }^{\circ} \mathrm{C}$. It seems that European Lucilia flies also have high thresholds for the activity. As for oviposition, it was suggested that $L$. sericata normally needs carcass surface temperatures above $30{ }^{\circ} \mathrm{C}$ to start this behavior [48]. It was also demonstrated that the oviposition rate of $L$. sericata increases with average daily temperature, and temperature at which this rate is 0 is about $11^{\circ} \mathrm{C}$ [49]. These results indicate that adult Lucilia flies have high temperature threshold for the activity (flying, locating a corpse, etc.), probably about $20^{\circ} \mathrm{C}$, and even higher threshold for oviposition. Temperatures below these thresholds will result in longer adult or oviposition PAI due to the lack of relevant activity of flies. Hence, we hypothesize that abrupt and erratic increase in $\mathrm{PAI}$, as recorded in a low temperature range for $L$. sericata and $L$. caesar, resulted simply from ambient air temperatures being below the threshold for the relevant activity. In order to check whether this was true, the raw temperature data were inspected. 
Interestingly, a similar pattern of temperature change was present in a majority of "high PAI" carcasses, i.e., an interval of low temperatures (approximately equal in length to PAI) followed by a substantial temperature increase before the first sampling of a given species and stage. Summarizing, current results corroborate the view that the PAI response to temperature in those insects which visit carcasses early in the decomposition process is better explained by the activity-oriented hypothesis than the processes-oriented hypothesis. The latter hypothesis is superior in the case of middle and late arrivers.

The strength of the relationship was generally weaker than expected. Apart from $S$. nigriceps, all the other species revealed at most weak premises for the estimation of PAI from temperature. When one compares current models with those for beetles [11], it is evident that the temperature-based estimation of PAI is more promising for beetles than flies. Differences between these models resulted, to some extent, from the methods used in this study. The resolution of sampling must have resulted in higher inaccuracy of PAIs in the early arrivers (flies) than in the late arrivers (beetles). Moreover, techniques of sampling, as being less effective for flies than beetles, must have given further inaccuracies of the PAI for flies. However, these methodical factors may not explain all the differences. It is suggested that factors related to the biology of flies and beetles or the nature of processes in which relevant attractants are produced may be more important. Anyway, further studies are needed.

Summarizing, only $S$. nigriceps revealed solid premises for estimating adult or oviposition PAI from temperature alone. In the case of the other species, temperature alone is a poor predictor for PAI, which suggests that models useful for the estimation of PAI in most carrion flies will be more complex. Therefore, future works should focus on other abiotic or biotic factors which may affect PAI in forensically useful flies.

Acknowledgments We would like to thank Captain R. Matera, Commander of the Biedrusko Military Range, and Z. Szelag, Forest Inspector of the Łopuchówko Forest Inspectorate, for granting access to the Biedrusko Military Range. Thanks are also extended to M. Jarmusz (Poznan, Poland) for the assistance in the field and laboratory work and K. Szpila (Torun, Poland) for the identification of adult and larval Piophilidae. The experiment was funded by the Ministry of Science and Higher Education (grants nos. IP2010025170 and IP2011034671).

Open Access This article is distributed under the terms of the Creative Commons Attribution License which permits any use, distribution, and reproduction in any medium, provided the original author(s) and the source are credited.

\section{References}

1. Wells JD, LaMotte LR (2010) Estimating the postmortem interval. In: Byrd JH, Castner JL (eds) Forensic entomology. The utility of arthropods in legal investigations. CRC, Boca Raton, pp 367-388
2. Amendt J, Campobasso CP, Gaudry E, Reiter C, LeBlanc H, Hall M (2007) Best practice in forensic entomology. Int J Legal Med 121:90 104

3. Villet M, Amendt J (2009) Advances in entomological methods for death time estimation. In: Turk EE (ed) Forensic pathology reviews, vol. 6. Springer, Berlin, pp 213-237

4. Amendt J, Richards CS, Campobasso CP, Zehner R, Hall M (2011) Forensic entomology: applications and limitations. Forensic Sci Med Pathol 7:379-392

5. Villet MH, Richards CS, Midgley JM (2010) Contemporary precision, bias and accuracy of minimum post-mortem intervals estimated using development of carrion-feeding insects. In: Amendt J, Campobasso CP, Goff ML, Grassberger M (eds) Current concepts in forensic entomology. Springer, Dordrecht, pp 109-138

6. Tomberlin JK, Mohr R, Benbow ME, Tarone AM, VanLaerhoven S (2011) A roadmap for bridging basic and applied research in forensic entomology. Ann Rev Entomol 56:401-421

7. Bourel B, Martin-Bouyer L, Hedouin V, Cailliez JC, Derout D, Gosset D (1999) Necrophilous insect succession on rabbit carrion in sand dune habitats in Northern France. J Med Entomol 36:420-425

8. Matuszewski S, Bajerlein D, Konwerski S, Szpila K (2011) Insect succession and carrion decomposition in selected forests of Central Europe. Part 3: succession of carrion fauna. Forensic Sci Int 207: $150-163$

9. Matuszewski S (2011) Estimating the pre-appearance interval from temperature in Necrodes littoralis L. (Coleoptera: Silphidae). Forensic Sci Int 212:180-188

10. Matuszewski S (2012) Estimating the pre-appearance interval from temperature in Creophilus maxillosus L. (Coleoptera: Staphylinidae). J Forensic Sci 57:136-145

11. Matuszewski S, Szafałowicz M (2013) Temperature-dependent appearance of forensically useful beetles on carcasses. Forensic Sci Int 229:92-99

12. Michaud JP, Moreau G (2009) Predicting the visitation of carcasses by carrion-related insects under different rates of degree-day accumulation. Forensic Sci Int 185:78-83

13. Archer MS (2004) The effect of time after body discovery on the accuracy of retrospective weather station ambient temperature corrections in forensic entomology. J Forensic Sci 49:553-559

14. Scala JR, Wallace JR (2010) Forensic meteorology: the application of weather and climate. In: Byrd JH, Castner JL (eds) Forensic entomology. The utility of arthropods in legal investigations. CRC, Boca Raton, pp 519-538

15. Johnson AP, Wallman JF, Archer MS (2012) Experimental and casework validation of ambient temperature corrections in forensic entomology. J Forensic Sci 57:215-221

16. Smith KG (1986) A manual of forensic entomology. The Trustees of the British Museum, London

17. Greenberg B, Kunich JC (2002) Entomology and the law. Flies as forensic indicators. Cambridge University Press, Cambridge

18. Byrd JH, Castner JL (2010) Insects of forensic importance. In: Byrd JH, Castner JL (eds) Forensic entomology. The utility of arthropods in legal investigations. CRC, Boca Raton, pp 39-126

19. Grassberger M, Frank C (2004) Initial study of arthropod succession on pig carrion in a central European urban habitat. J Med Entomol 41: $511-523$

20. Anton E, Niederegger S, Beutel RG (2011) Beetles and flies collected on pig carrion in an experimental setting in Thuringia and their forensic implications. Med Vet Entomol 25:353-364

21. Prado E, Castro C, Serrano A, da Silva Martins P, Garcia MD (2012) Carrion flies of forensic interest: a study of seasonal community composition and succession in Lisbon, Portugal. Med Vet Entomol 26:417-431

22. Benbow ME, Lewis AJ, Tomberlin JK, Pechal JL (2013) Seasonal necrophagous insect community assembly during vertebrate carrion decomposition. J Med Entomol 50:440-450 
23. Szpila K (2010) Key for the identification of third instars of European blowflies (Diptera: Calliphoridae) of forensic importance. In: Amendt J, Campobasso CP, Goff ML, Grassberger M (eds) Current concepts in forensic entomology. Springer, Dordrecht, pp 43-56

24. Szpila K (2012) Key for identification of European and Mediterranean blowflies (Diptera, Calliphoridae) of medical and veterinary importance - adult flies. In: Gennard D (ed) Forensic entomology. An introduction. Willey-Blackwell, Chichester, pp 77-81

25. Gregor F, Rozkošný R, Barták M, Vanhara J (2002) The Muscidae (Diptera) of Central Europe. Folia Biologia, Brno

26. McAlpine JF (1977) A revised classification of the Piophilidae including 'Neotophilidae' and 'Tyreophoridae' (Diptera: Schizophora). Mem Entomol Soc Can 103:1-66

27. Stensmyr MC, Urru I, Collu I, Celander M, Hansson BS, Angioy AM (2002) Rotting smell of dead-horse arum florets. Nature 420:625-626

28. Kalinová B, Podskalská H, Růžička J, Hoskovec M (2009) Irresistible bouquet of death - how are burying beetles (Coleoptera: Silphidae: Nicrophorus) attracted by carcasses. Naturwissenschaften 96:889-899

29. Frederickx C, Dekeirsschieter J, Verheggen FJ, Haubruge E (2012) Responses of Lucilia sericata Meigen (Diptera: Calliphoridae) to cadaveric volatile organic compounds. J Forensic Sci 57:386-390

30. Dekeirsschieter J, Frederickx C, Lognay G, Brostaux Y, Verheggen FJ, Haubruge E (2013) Electrophysiological and behavioral responses of Thanatophilus sinuatus Fabricius (Coleoptera: Silphidae) to selected cadaveric volatile organic compounds. J Forensic Sci 58:917-923

31. vonHoermann C, Ruther J, Reibe S, Madea B, Ayasse M (2011) The importance of carcass volatiles as attractants for the hide beetle Dermestes maculatus (De Geer). Forensic Sci Int 212:173-179

32. vonHoermann C, Steiger S, Müller JK, Ayasse M (2013) Too fresh is unattractive! The attraction of newly emerged Nicrophorus vespilloides females to odour bouquets of large cadavers at various stages of decomposition. PLoS ONE 8:e58524. doi:10.1371/journal.pone.0058524

33. Dekeirsschieter J, Verheggen FJ, Gohy M, Hubrecht F, Bourguignon L, Lognay G, Haubruge E (2009) Cadaveric volatile organic compounds released by decaying pig carcasses (Sus domesticus L.) in different biotopes. Forensic Sci Int 189:46-53

34. Paczkowski S, Schütz S (2011) Post-mortem volatiles of vertebrate tissue. Appl Microbiol Biotechnol 91:917-935

35. Campobasso CP, Di Vella G, Introna F (2001) Factors affecting decomposition and Diptera colonization. Forensic Sci Int 120:18-27
36. Richards CS, Price BW, Villet MH (2009) Thermal ecophysiology of seven carrion-feeding blowflies in Southern Africa. Entomol Exp Appl 131:11-19

37. George KA, Archer MS, Toop T (2013) Abiotic environmental factors influencing blowfly colonization patterns in the field. Forensic Sci Int 229:100-107

38. Marchenko MI (2001) Medicolegal relevance of cadaver entomofauna for the determination of the time of death. Forensic Sci Int 120:89 109

39. Charabidze D, Bourel B, Hedouin V, Gosset D (2009) Repellent effect of some household products on fly attraction to cadavers. Forensic Sci Int 189:28-33

40. Shelomi M, Matern LM, Dinstell JM, Harris DW, Kimsey RB (2012) DEET ( $N, N$-diethyl-meta-toluamid) induced delay of blowfly landing and oviposition rates on treated pig carrion (Sus scrofa L.). J Forensic Sci 57:1507-1511

41. Amendt J, Zehner R, Reckel F (2007) The nocturnal oviposition behavior of blowflies (Diptera: Calliphoridae) in Central Europe and its forensic implications. Forensic Sci Int 175:61-64

42. Baldridge R, Wallace S, Kirkpatrick R (2006) Investigation of nocturnal oviposition by necrophilous flies in Central Texas. J Forensic Sci 51:125-126

43. Woodridge J, Scrace L, Wall R (2007) Flight activity of the blowflies, Calliphora vomitoria and Lucilia sericata, in the dark. Forensic Sci Int 172:94-97

44. Zurawski KN, Benbow ME, Miller JR, Merritt RW (2009) Examination of nocturnal blow fly (Diptera: Calliphoridae) oviposition on pig carcasses in mid-Michigan. J Med Entomol 46:671-679

45. Berg MC, Benbow ME (2013) Environmental factors associated with Phormia regina (Diptera: Calliphoridae) oviposition. J Med Entomol 50:451-457

46. Barton Browne L, Bartell RJ, Shorey HH (1969) Pheromonemediated behaviour leading to group oviposition in the blowfly Lucilia cuprina. J Insect Physiol 15:1003-1014

47. Cruickschank I, Wall R (2002) Aggregation and habitat use in Lucilia blowflies (Diptera: Calliphoridae) in pasture. Bull Entomol Res 92: $153-158$

48. Cragg JB (1956) The olfactory behaviour of Lucilia species (Diptera) under natural conditions. Ann Appl Biol 44:467-477

49. Pitts KM, Wall R (2004) Adult mortality and oviposition rates in field and captive populations of the blowfly Lucilia sericata. Ecol Entomol 29:727-734 